\title{
Prevalence of intestinal parasites in children from minority group with low hygienic standards in Slovakia
}

\author{
P. RUDOHRADSKÁ ${ }^{1}$, M. HALÁNOVÁ ${ }^{2 *}$, P. RAVASZOVÁ ${ }^{3}$, M. GOLDOVÁ ${ }^{4}$, A. VALENČÁKOVÁ ${ }^{3}$, \\ M. HALÁN ${ }^{4}$, I. PAPAJOVÁ ${ }^{1}$, A. POHORENCOVÁ ${ }^{2}$, J. VALKO ${ }^{2}$, L. ČISLÁKOVÁ ${ }^{2}$, P. JURIŠ ${ }^{2}$
}

\begin{abstract}
${ }^{1}$ Parasitological Institute of the Slovak Academy of Sciences, Hlinkova 3, 04001 Košice, Slovak Republic; ${ }^{2}$ Department of Public Health, Pavol Jozef Šafárik University, Faculty of Medicine, Šrobárová 2, 04180 Košice, Slovak Republic, ${ }^{*}$ E-mail: monika.halanova@upjs.sk $;{ }^{3}$ Department of Biology and Genetics, University of Veterinary Medicine and Pharmacy, Komenského 73, 04181 Košice, Slovak Republic; ${ }^{4}$ Department of Epizootology and Parasitology, University of Veterinary Medicine and Pharmacy, Komenského 73, 04181 Košice, Slovak Republic
\end{abstract}

\begin{abstract}
Summary
The number of parasites followed the rapid growing of human population worldwide, not only in developing but also in developed countries. Many of them are diagnosed in children and adolescents. The occurrence of selected intestinal endoparasites in children coming from areas with low hygienic and socioeconomic status was studied. Out of 81 faecal samples examined, 46 (56.8\%) were positive for presence of intestinal parasites. From helminths, Ascaris lumbricoides was found to be the leading parasite (24.7\%), followed by Trichuris trichiura (17.3\%). Tapeworm Taenia spp. eggs were detected in $4.9 \%$ of examined children. From protozoan parasites Cryptosporidium spp. was observed in 36 children $(44.4 \%)$ and Giardia intestinalis in 20 children $(24.7 \%)$. The occurrence of these epidemiologically low risky parasites in Roma children population suggests low hygienic standard in the Roma settlements.
\end{abstract}

Keywords: ascariosis; trichuriosis; taeniosis; cryptosporidiosis; giardiosis; children; Roma settlements

\section{Introduction}

In present, intestinal parasitic infections remain a serious public health problem in both developed and developing countries. Giardia intestinalis and amoebae, together with Cryptosporidium spp. belong to the most commonly detected intestinal protozoa. From a group of helminths there are Ascaris lumbricoides, Trichuris trichiura, Enterobius vermicularis, hookworms, and tapeworms Taenia spp.

It is well known that all of these infections are very often endemic in places with poor sanitation and crowded living conditions and are associated with source of water, age, and socioeconomic status of community. In Slovakia, such

${ }^{*}$ corresponding author places are largely represented by the Roma settlements and housing.

Estimations of the total number of Roma living across Europe range from 10 to 12 million people (Rimárová, 2010). In Slovakia, according to the Statistical Office of the Slovak Republic there are from total 5379455 citizens 89947 of Roma nationality, what represents $1.67 \%$ only (Statistical Office of the Slovak Republic, 2001), however, estimated number of Roma citizens in Slovakia ranges from 480000 to 520000 with percentage of the total population between 9.0 to $9.7 \%$ (Liegois \& Gheorghe, 1995). Also the fact that almost half of the Roma population in Slovakia is younger than 18 years old is very important (Popper et al., 2009; Rimárová, 2010).

Material dimension of poverty in Roma national minority is particularly noticeable in the sphere of living. Especially, in the segregated settlements with illegal huts (mostly built of wood, iron waste, flat metal stock and other materials obtained from waste dumps or surrounding countryside), devastated environment and with no access to basic infrastructure such as electricity, tap water (they mostly use water wells or streams), sewerage system and waste disposal what in many cases has influence on bad health status and troubles with hygiene.

According to several studies, many settlements, which are often built on loose soils, are lacking drinking water, sewage, waste pits and landfills, sanitary facilities and garbage disposal.

Therefore, the aim of this work was to study the occurrence of selected endoparasites obtained by coprological survey in Roma children population coming from Roma settlements in selected areas of Eastern Slovakia.

\section{Material and methods}

A total of 81 faecal samples of clinically healthy Roma 
children population were examined for the presence of intestinal parasites. Children coming from selected areas of Eastern Slovakia, especially from Roma settlements of Košice and Prešov regions, were divided into 4 groups according to their age. In the $1^{\text {st }}$ group there were children younger than one year $(n=40)$, in the $2^{\text {nd }}$ group there were children between 1 to 5 years $(n=19)$, in the $3^{\text {rd }}$ group there were children between 6 to 9 years $(n=12)$, and in the $4^{\text {th }}$ group there were 10 to 14 years old children $(\mathrm{n}=$ 10), (Table 1).
None of examined children had clinical signs typical for helminthoses, cryptosporidiosis or giardiosis.

Samples were examined also for Cryptosporidium spp. by the ELISA method. Cryptosporidium antigen was detected in all of examined groups with the highest positivity in the group of 5 to 9 years old children $(58.3 \%)$, (Table 1$)$. All faecal samples were parallelly examined by the modified Kinyoun's acid-fast stain also, which had a lower detection rate. The finding of large numbers of Cryptosporidium spp. oocysts was observed mostly at absorbance between 0.575

Table 1. Occurrence of selected endoparasites in relation to age structure of examined children

\begin{tabular}{|c|c|c|c|c|c|c|c|c|c|c|}
\hline \multirow{2}{*}{ Age } & \multicolumn{2}{|c|}{ Cryptosporidium spp. } & \multicolumn{2}{|c|}{$\begin{array}{c}\text { Giardia } \\
\text { intestinalis }\end{array}$} & \multicolumn{2}{|c|}{ Trichuris trichiura } & \multicolumn{2}{|c|}{$\begin{array}{c}\text { Ascaris } \\
\text { lumbricoides }\end{array}$} & \multicolumn{2}{|c|}{ Taenia spp. } \\
\hline & $\mathrm{P}$ & $\%$ & $\mathrm{P}$ & $\%$ & $\mathrm{P}$ & $\%$ & $\mathrm{P}$ & $\%$ & $\mathrm{P}$ & $\%$ \\
\hline $\begin{array}{c}<1 \\
(n=40)\end{array}$ & 16 & 40 & 5 & 12.5 & 4 & 10.0 & 6 & 15.0 & - & - \\
\hline $\begin{array}{c}1-5 \\
(n=19)\end{array}$ & 9 & 47.4 & 6 & 66.7 & 4 & 21.1 & 5 & 26.1 & 1 & 5.3 \\
\hline $\begin{array}{c}6-9 \\
(n=12)\end{array}$ & 7 & 58.3 & 6 & 50 & 4 & 33.3 & 5 & 41.7 & 2 & 16.7 \\
\hline $\begin{array}{l}10-14 \\
(n=10)\end{array}$ & 4 & 40 & 3 & 30 & 2 & 20.0 & 4 & 40.0 & 1 & 10.0 \\
\hline
\end{tabular}

For separation of helminths eggs and protozoan cysts zinc sulphate flotation concentration method was used. The parasitic elements were recovered from the surface film of $33 \%$ zinc sulphate solution with specific gravity 1.18 . The faecal samples were also analysed by a modified Kinyoun's acid-fast stain, specific method for detection of Cryptosporidium spp. oocysts (Garcia \& Bruckner, 1997). Samples were subsequently examined microscopically using light microscope (Olympus BX41) at 400 x magnifications.

The samples were examined also by the ELISA method using commercial kit Cryptosporidium ELISA (f. Diagnostic Automation, INC, Calabasas, CA). This ELISA is an in vitro immunoassay for the qualitative determination of Cryptosporidium antigen in faeces. In this double antibody (sandwich) ELISA, an anti-Cryptosporidium polyclonal antibody to capture the antigen from the stool supernatant is used. In the case of a positive immunological reaction to the presence of Cryptosporidium antigen, the absorbance (450/630 nm, ELISA Reader Opsys MR Thermo Labsystems) was read of 0.15 OD units and above. Absorbance reading less than 0.15 OD units indicates the sample does not contain detectable levels of Cryptosporidium antigen.

\section{Results}

Out of 81 faecal samples examined, 46 (56.8 \%) were positive for presence of intestinal parasites. Detected intestinal helminths and protozoa are demonstrated in Fig. 1. Ascaris lumbricoides was found to be the leading parasite (24.7\%), followed by Trichuris trichiura (17.3\%). Tapeworm Taenia spp. eggs were detected in all groups, except of the $1^{\text {st }}$ group ( $<1$ year), in 4 samples overall $(4.9 \%)$.
OD to 2.066 OD.

Giardia intestinalis was detected in $20(24.7 \%)$ out of the total number of 81 examined samples (Table 1). The highest occurrence $(66.7 \%)$ of positive samples was found in the $2^{\text {nd }}$ group $(1-5$ years $)$.

According to statistical evaluation, no significant differences between positive cases in individual age categories were observed.

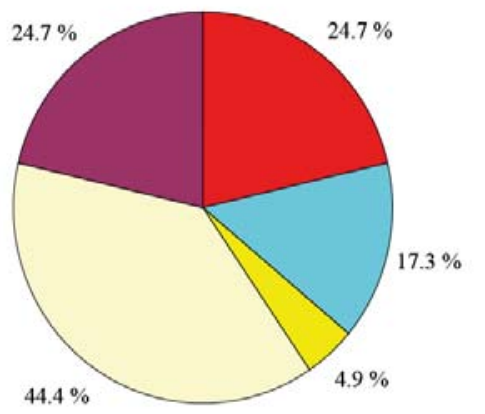

Ascaris humbricoides

$\square$ Trichuris trichiura

$\square$ Taenia spp.

$\square$ Cryptosporidintm spp.

a Giardia intestinalis

Fig. 1. Prevalence of intestinal parasites in children

\section{Discussion}

Parasitic infections have high prevalence rates throughout the world and it is estimated that more than three billion people are infected with intestinal parasites in the world (Markell et al., 1999). Their occurrence is frequently observed in areas with poor hygiene and bad socioeconomic status.

According to the Office of Government Plenipotentiary for Roma Issue in Slovakia there are approximately 680 Roma settlements at present, which are often located in rural areas without the necessary basic infrastructure. The settle- 
ments are concentrated in small areas with a large number of people whose health status is unsatisfactory. The key determinants of health undoubtedly include not only housing, but also drinking water. In numerous settlements, there are only single water wells serving all the residents, and the quality of water is not being monitored regularly (Rimárová, 2010).

In our study we examined 81 children coming from Roma settlements for the presence of selected intestinal parasites - Trichuris trichiura, Ascaris lumbricoides, Taenia spp., Cryptosporidium spp. and Giardia intestinalis. All these parasites belong to the zoonotic species with the occurrence in both developed and developing countries.

For epidemiology and spread of Cryptosporidium there are five important remarkable characteristics: its impressively hardy oocysts that are highly resistant to chlorine and to acid, its relatively small size, its apparent low infectious dose, its fully sporulated and infectious nature immediately upon shedding, and its zoonotic potential (at least for strains other than C. parvum, genotype 1), (Dillingham et al., 2002). These facts, together with poor health conditions and low living standards are likely to cause a relatively high percentage of positive samples to Cryptosporidium spp. in Roma children.

In current study Cryptosporidium spp. was detected in $44.4 \%$ of samples, with the highest positivity in the $3^{\text {rd }}$ group of children 6 to 9 years old $(58.3 \%)$ and $2^{\text {nd }}$ group of children 1 to 5 years old $(47.3 \%)$. Generally, the prevalence of Cryptosporidium spp. in human ranges from 2.6 to $21.3 \%$ in African countries, from 3.2 to $31.5 \%$ in Central and South American countries, from 1.3 to $13.1 \%$ in Asian countries, and from 0.1 to $14.1 \%$ in European (Ungar, 1990; Fayer, 2004). In a group of children the epidemiological situation is different, and the prevalence is higher, especially in malnourished children living in impoverished, developing areas with poor hygiene (Checkley et al., 1997, 1998; Newman et al., 1999; Lima et al., 2000). Many studies confirmed that peak incidence of cryptosporidiosis is seen among children aged $1-5$ years (Meinhardt et al., 1996). Children may have recurrent episodes of cryptosporidiosis, indicating that acquired immunity to cryptosporidial infection is only short or incomplete (Newman et al., 1999). In industrialized countries, the occurrence of endemic cryptosporidiosis is usually associated with consumption of contaminated food or water (Quiroz et al., 2000).

In our research, relatively high positivity of Giardia intestinalis (24.7\%), Ascaris lumbricoides (24.7\%) and Trichuris trichiura $(17.3 \%)$ were detected. There are no recent data on prevalence of intestinal parasites from majority population to compare with our results, however, during two-year study, Königová et al. (2010) reported $2.55 \%$ rate of infections with a common roundworm and/or whipworm in the group of hospitalised children what indicates that these infections have not been eradicated in Slovakia.

Similar studies have been performed worldwide in the areas with low hygienic standards. Ares-Mazas et al. (1987) analysed 1000 faecal samples from apparently healthy children ( $0-15$ years old) from Galicia (Spain). Results showed that $31.8 \%$ of children had intestinal parasitic infection. Giardia intestinalis was detected in $8.7 \%$, Ascaris lumbricoides in $4.3 \%$, and Trichuris trichiura in $18.0 \%$. Spinelli et al. (2006) evaluated the prevalence of intestinal parasites in 277 healthy persons in the city Mamuras in the south eastern Albania. Total prevalence of parasites was $24.18 \%$, including Giardia intestinalis (11.19\%), Ascaris lumbricoides (1.08\%), and Trichuris trichiura $(12.27 \%)$.

In another study, Plonka \& Dzbenski (1999) examined over 30 thousand faecal samples of 7-year old children in their first year of elementary school in 25 provinces of Poland. The study shoved overall prevalence of endoparasites $21.55 \%$ (15.92\% in towns and $31.52 \%$ in the villages). The parasites encountered were: Giardia intestinalis (1.0 \%), Ascaris lumbricoides (2.8\%), Trichuris trichiura $(0.29 \%)$. Five years later faecal samples obtained from 31,504 children ( 7 year old) were examined from the same regions of Poland (Bitkowska et al., 2004). The most frequent parasites were Giardia intestinalis $(0.67 \%)$, Ascaris lumbricoides $(0.83 \%)$, Trichuris trichiura $(0.12 \%)$. The incidence of intestinal parasitic infection was higher in children from urban areas $(19.0 \%)$ than in children from rural areas $(10.4 \%)$.

Biadun et al. (2001) during 24 years examined a total of 2828 children from a Home for the mentally handicapped in Lublin region (Poland) for intestinal parasites. Total prevalence of endoparasites was $45.9 \%$, of which Giardia intestinalis was detected in $1.3 \%$, Ascaris lumbricoides in $3.0 \%$, Trichuris trichiura in $7.8 \%$ and Enterobius vermicularis in $40.5 \%$.

Faecal samples of 514 immigrants in Naples (southern Italy) living as a marginalised population were tested. Total prevalence of parasites was $61.9 \%$; the most prevalent species were Giardia intestinalis (4.5\%), Ascaris lumbricoides (1.4\%), Trichuris trichiura (3.9\%), and Taenia spp. (0.2\%) (Gualdieri et al., 2011). Dabrowiecki et al. (2009) investigated the prevalence of parasites among 426 children $(1-18$ years old) of Chechen refugees residing in Poland. The result shoved $33.8 \%$ total prevalence. Giardia intestinalis was the prevailing species $(22.8$ $\%$ ). Most prevalent helminthes were Strongyloides stercoralis $(6.8 \%)$, Ascaris lumbricoides (5.6\%) and Enterobius vermicularis (1.4 \%). Dabrowiecki et al. (2009) pointed that an increased risk for the occurrence of parasitic diseases with epidemic character among the local population exists. Turrientes et al. (2001) examined 989 immigrants in Madrid (Spain) mostly from Africa. Total prevalence of protozoans in children faecal samples was $16.9 \%$, the most common being Entamoeba coli (5.5\%) and Giardia intestinalis $(3.5 \%)$. From the group of intestinal helminths, the most frequently diagnosed were Ascaris lumbricoides (6.9\%) and Trichuris trichiura (6.1\%).

As it is apparent, the occurrence of intestinal parasitic infections is higher in the group of children with lower socioeconomic status in comparison with the group of healthy children living in good conditions. 


\section{Acknowledgement}

This work was partially supported by the Agency of the Slovak Ministry of Education for the Structural Funds of the EU, under project ITMS: 26220120058 (50\%) and by VEGA MŠ SR No. 2/0147/10 (40\%), 1/0831/12, and 1/0023/11.

\section{References}

Ares-Mazas, M. E., Sela-Perez, M. C., FandinoSalorio, M. L., Arias-Fernandez, M. C. (1987): Prevalence of enteric parasite infections among children in Galicia. Rev. Iber. Parasitol., 47 (3): 247 - 252

Biadun, W., Chybowski, J., Rukasz, H., Stanios, H. (2001): Occurrence of gastrointestinal parasites in children in Lublin region in the period 1976-2000. Wiadom. Parazytol., 47 (3): $417-422$

Bitkowska, E., Wnukowska, N., WoJTyniak, B., DZBENSKI, T. H. (2004): The occurrence of intestinal parasites among children attending first classes of the elementary schools in Poland in the school year 2002/03. Przeglad Epidemiol., 58 (2): 295 - 302

Checkley, W., Gilman R. H., Epstein, L. H., Suarez, M., Diaz, J. F., Cabrera, L., Black, R. E., Sterling, C. R. (1997) Asymptomatic and symptomatic cryptosporidiosis: their acute effect on weight gain in Peruvian children, Am. J. Epidemiol., 145: 156 - 163

Dabrowiecki, Z., Korzeniewski, K., Morawiec, B., DABROWIECKA, M., OLSZANSKI, R. (2009): Intestinal helminthes and protozoan infections among children of Chechen refugees in Poland. Exp. Med., 1 (1): $14-18$

Dillingham, R. A., Lima, A. A., Guerrant, R. L. (2002): Cryptosporidiosis: epidemiology and impact. Microb. Infect., 4: 1059 - 1066. DOI: 10.1016/S1286-4579(02)01630-1

FAYER, R. (2004): Cryptosporidium: a water-borne zoonotic parasite. Vet. Parasitol., 126: 37 - 56. DOI: 10.1016/j.vetpar.2004.09.004

Garcia, L. S., BruCKnER, D. A. (1997): Diagnostic Medical Parasitology. ASM Press, Washington DC, 937 pp

Gualdieri, L., Rinaldi, L., Petrullo, L., Morgoglione, M. E., Maurelli, M. O., Musella, V., Piemonte, M., Caravano, L., Coppola, M. G., Cringoli, G. (2011): Intestinal parasites in immigrants in the city of Naples (southern Italy). Acta Trop., 117 (3): 196 - 201. DOI: 10.1016/j.actatropica.2010.12.003

Liegois, J. P., GHEORGhe, N. (1995): Roma Gypsies: A European Minority. London Minority Rights Group Report.

Königová, A. KinČEKovÁ, J., HrČKovÁ, G., VelebnÝ, S., VÁrady, M., PAVlinovÁ, J., Kuchta, M. (2010): Nematode infections in Slovak children hospitalised during
2008 - 2009. Helminthologia, 47, 4: 204 - 211. DOI: 10.2478/s11687-010-0032-9

Lima, A. M., Moore, S. R., Barboza, M. S., SoAres, A. M., Schleupner, M. A., Newman, R. D., Sears, C. L., NAtaro, J. P., Fedorko, D. P., Wuhib, T., Schorling, J. B., Guerrant, R. L. (2000): Persistent diarrhea signals a critical period of increased diarrhea burdens and nutritional shortfalls: a prospective cohort study among children in northeastern. Brazil. J. Infect. Dis., 181: 1643 - 1651, DOI: $10.1086 / 315423$

MARKell, E. K., John, D. T., Krotoski, W. A. (1999): Markell and Voge's Medical Parasitology. 8th Edition. Philadelpia, W. B. Saunders Company USA, 501 pp.

Meinhardt, P. L., Casemore, D. P., Miller, K. B. (1996): Epidemiological Aspects of Human Cryptosporidiosis and the Role of Waterborne Transmission. Epidemiol. Rev., 2: $118-136$

Newman, R. D., Sears, C. L., Moore, S. R., Nataro, J. P., Wuhib, T., Agnew, D. A., Guerrant, R. L., Lima, A. M. (1999): Longitudinal study of Cryptosporidium infection in children in northeastern Brazil. J. Infect. Dis., 180: 167 - 175. DOI: 10.1086/314820

PlonkA, W., DzBENSKI, T. H. (1999): The occurrence of intestinal parasites among children attending first classes of elementary schools in Poland in the school year 1997/1998. Przeglad Epidemiol., 53 (3 - 4): 331 - 338

PopPer, M., SzEGHY, P., SÁRKÓZY, Š. (2009): Roma population in Slovakia and health: analysis of the situation in Slovakia, Bratislava, PDSC, 95 pp (In Slovak)

RimÁrovÁ, K. (2010): The Health of the Roma people in Central and Eastern Europe. Pavol Jozef Šafárik University in Košice, Equilibria, 99 pp

Statistical Office of Slovak Republic (2001): Population and Housing Census. Bratislava, Report, 2031 pp Spinelli, R., Brandonisio, O., Serio, G., Trerotoli, P., Ghezzani, F., CArito, V., Dajci, N., Doci, A., PiCAKU, F., DENTICO, P. (2006): Intestinal parasites in healthy subjects in Albania. Eur. J. Epidemiol., 21 (2): 161 - 166. DOI: 10.1007/s10654-005-5926-3

Turrientes, M. C., Huerga, H., Lopez-Velez R. (2001): Parasitic diseases in a cohort of immigrants in Madrid, Spain. Rev. Iber. Parasitol., 61 (1 - 2): $48-58$

Ungar B. L. P. (1990): Cryptosporidiosis in humans (Homo Sapiens). In: Dubey JP, Speer CA, Fayer R (Eds.) Cryptosporidiosis in Man and Animals. CRC Press, Boca Raton, FL. 59 - 84

Quiroz, E. S., Bern, C., Macarthur, J. R., XiaO, L., Fletcher, M., Arrowood, M. J., Shay, D. K., Levy, M. E., GLASS, R. I., LAL, A. (2000): An outbreak of cryptosporidiosis linked to a foodhandler. J. Infect. Dis., 181: 695 - 700. DOI: $10.1086 / 315279$ 